\title{
Differential Impact of Food Insecurity, Distress, and Stress on Self-care Behaviors and Glycemic Control Using Path Analysis
}

\author{
Rebekah J. Walker, $P h D^{1,2}$, Jennifer A. Campbell, MPH ${ }^{1,2,3}$, and Leonard E. Egede, MD, \\ $M S^{1,2,3}$
}

'Division of General Internal Medicine, Department of Medicine, Medical College of Wisconsin, Milwaukee, WI, USA; ${ }^{2}$ Center for Advancing Population Science, Medical College of Wisconsin, Milwaukee, WI, USA; ${ }^{3}$ University of Wisconsin, Milwaukee, Joseph Zilber School of Public Health, Milwaukee, WI, USA.

BACKGROUND:The aim of this study was to investigate the direct and indirect pathways through which food insecurity influences glycemic control and self-care behaviors.

METHODS: Using data collected from 615 adults with type 2 diabetes, we investigated pathways between food insecurity and diabetes outcomes using path analysis. We included measures of perceived stress, diabetes distress, diabetes fatalism, and depression as psychosocial factors in the pathway. Self-care behaviors included general diet, specific diet, exercise, blood sugar testing, foot care, and medication adherence. Analyses were conducted using Stata v14, to include both direct and indirect effects, with standardized estimates to allow comparison of paths.

RESULTS: Food insecurity was directly associated with stress $(r=0.43, p<0.001)$, depression $(r=0.34, p<0.001)$, fatalism $(r=0.09, p=0.03)$, and distress $(r=0.36, p<0.001)$. The type of stress, however, was differentially associated with outcomes, with distress associated with HbAlc ( $r=$ $0.25, p<0.001)$, general and specific diet $(r=-0.28$ and 0.17 , respectively, $p=0.001)$, and medication adherence $(r=$ $-0.26, p<0.001)$, while stress was associated with specific $\operatorname{diet}(r=-0.14, p=0.005)$ and medication adherence $(r=-$ $0.15, p<0.001$ ) and depression was associated with exercise ( $r=-0.06, p=0.007$ ). Food insecurity was indirectly associated with $\mathrm{HbAlc}(r=0.08, p=0.001)$, and four self-care behaviors (general diet, specific diet, exercise, and medication adherence).

CONCLUSIONS: Food insecurity influences self-care behaviors indirectly via multiple psychosocial factors, and glycemic control indirectly through diabetes distress, supporting the hypothesis that stress is an important mechanism. Programs to improve access to resources and manage psychosocial concerns should be combined with foodbased programs for food insecure populations with diabetes.

KEY WORDS: food insecurity; stress; distress; epression; self-care behaviors.

J Gen Intern Med 34(12):2279-85

DOI: $10.1007 / \mathrm{s} 11606-019-05427-3$

(๑) Society of General Internal Medicine 2019

Received March 20, 2019

Revised July 26, 2019

Accepted September 16, 2019

Published online October 16, 2019

\section{INTRODUCTION}

Food insecurity, inconsistent or undependable access to sufficient food due to money or other resources, is associated with poor health outcomes, particularly in individuals with chronic disease. ${ }^{1-4}$ The most recent national estimates show declines in food insecurity at the population level from $12.3 \%$ in 2016 to $11.8 \%$ of households in 2017 , that is approximately 15 million households, with certain populations experiencing food insecurity at a higher rate. ${ }^{1,5-7}$ For example, often individuals from racial/ethnic minority groups report higher levels of food insecurity, and over 30\% of households with incomes below $185 \%$ of the poverty threshold reported food insecurity in the prior year. ${ }^{1,8}$ In addition, individuals with cardiometabolic disease, who need to modify their diet to manage disease, are more likely to report food insecurity than those without disease, with nearly $28 \%$ of the population with diabetes report being food insecure. ${ }^{5}$ In addition, prevalence in groups with undiagnosed diabetes has increased more dramatically than those diagnosed, suggesting changes in diet due to physician recommendations may not explain the full picture. ${ }^{6}$

Food insecure individuals report poorer overall health, more comorbid conditions, greater psychological distress, and poor health behaviors, including low physical activity and low consumption of fruits and vegetables. ${ }^{2,9-11}$ In addition, food insecurity is associated with $50 \%$ higher risk of diabetes, $21 \%$ higher risk of hypertension, worse glycemic control, and poor lipid control in those with diabetes. ${ }^{12-15}$ Though there is limited information on biological mechanisms, it has been found that food insecurity in the prior 30 days is associated with more inflammation, higher central adiposity, and greater insulin resistance. ${ }^{16}$ It is hypothesized that stress from changes in dietary patterns lead to inflammation and immune responses, which ultimately result in increased diabetes risk and poor diabetes outcomes. ${ }^{16}$ In addition, evidence suggests food insecurity influences decisions regarding diabetes selfcare beyond diet, increased diabetes distress, and may lower diabetes self-efficacy. ${ }^{11,14,17-20}$

Given the possible biological influence of limited access to nutritional foods, and the psychosocial impact of consistent worry regarding availability of food, feelings of deprivation, 
and increased requirement to cope with restricted food choices, food insecurity can be considered a chronic stressor leading to poor mental and physical health. ${ }^{21-23}$ However, there has been limited research investigating the stress pathway in food insecure populations, in a way that can direct development of behavioral interventions. ${ }^{10}$ Food insecure individuals report higher prevalence of depression, perceived stress, and diabetes distress than individuals with diabetes who are food secure, but studies have provided mixed results on possible mediators of these relationships. ${ }^{2,16,24}$ For example, examination of coping strategies used to manage economic stress in individuals with diabetes did not explain the relationship between food insecurity and poor glucose control. ${ }^{14,25}$ Additionally, when looking at mediation, difficulty following a diet was an important factor; however, it only mediated $20 \%$ of the relationship between food insecurity and glycemic control. ${ }^{14,25}$ Moreover, while depression, diabetes distress, and medication adherence attenuated the relationship between food insecurity and glycemic control, it did not remove the significance indicating another factor mediates the relationship. ${ }^{20}$ Finally, a path analysis in individuals with diabetes found that food insecurity had independent pathways to glycemic control and self-care, with the relationship to self-care occurring indirectly through perceived stress. ${ }^{26}$

Given, diabetes now affects $14 \%$ of the adult population, ${ }^{27}$ a comprehensive analysis of the possibly direct and indirect pathways between food insecurity and glycemic control is warranted. Therefore, the aim of this study was to investigate the pathway through which food insecurity influences glycemic control, taking into account a variety of stress and distress measures and self-care behaviors.

\section{METHODS}

\section{Sample}

Data for this cross-sectional study was collected from 615 adults with type 2 diabetes recruited from primary care clinics. All procedures were approved by the local institutional review board prior to enrollment. Eligibility criteria included ${ }^{1}$ age 18 or older, ${ }^{2}$ diagnosis by a healthcare professional in the medical record of type 2 diabetes, and ${ }^{3}$ ability to communicate in English. Participants were ineligible if cognitive impairment was demonstrated, keeping them from being able to validly answer questions. Recruitment methods included mailed letters of invitation or direct invitation by a research coordinator in the clinic. After informed consent procedures, participants completed a self-administered survey that consisted of a number of validated questionnaires.

\section{Outcome-HbAlc}

Following completion of the survey, study coordinators abstracted hemoglobin A1c (HbA1c) from the medical record.
The most recent $\mathrm{HbAlc}$ was used from the 6 months prior to the day a participant completed the survey.

\section{Food Insecurity}

Food insecurity was measured using the 6 -item validated scale developed by the US Department of Agriculture (USDA). ${ }^{28,29}$ Items allow classification of food secure, moderately food insecure, and very food insecure for household with and without children. Questions ask about whether over the past 12 months respondents have enough money to buy food, if they had to cut meals or ate less because there was not enough money, if they could afford to each balanced meals, and if they were still hungry but did not eat more because of money. ${ }^{28,29}$ As the frequency of these experiences increases, the score is higher, such that higher scores indicate greater levels of food insecurity.

\section{Psychosocial Factors}

Depression was measured using the validated PHQ-9 questionnaire which asks respondents to indicate over the past 2 weeks how frequent they experience 9 DSM-IV criteria used to diagnose depression. ${ }^{30}$ Higher scores indicate higher burden of depressive symptoms, with cut-points determined to represent mild, moderate, and severe depression. Scores have been shown to have reasonable sensitivity and specificity for clinically diagnosed depression when using a cut-point of greater than or equal to $10 .{ }^{30}$

Diabetes fatalism was measured using the 12-item Diabetes Fatalism Scale, which was designed to identify fatalistic attitudes in patients with diabetes including feeling of distress, powerlessness, hopelessness, and a lack of self-efficacy. ${ }^{31}$ The Diabetes Fatalism Scale has been shown to have a Cronbach alpha of 0.804 indicating high internal consistency, and correlates well with self-management and mental health-related quality of life. ${ }^{31}$

Perceived stress was measured using the 4-item Perceived Stress Scale, which indicates in the past month, the degree to which a respondent finds general life situations stressful. ${ }^{32}$ The Perceived Stress Scale has been shown to have a Cronbach alpha of 0.69 , and scores are highly correlated with other measures of stress, depression, and anxiety. ${ }^{33}$ Respondents rate the frequency of feelings of stress over the past 30 days, such that higher scores indicate higher levels of stress. ${ }^{32}$

Diabetes distress was measured using the 17-item Diabetes Distress Scale, which measures the level of distress due to disease management, support for care, emotional burden of disease, and access to the necessary care for disease. ${ }^{34}$ Respondents indicate the level with which each question is a problem from "not a problem" to "a very serious problem" so that higher scores indicate higher levels of distress. ${ }^{34}$ The Diabetes Distress Scale has been validated in a number of diabetes populations and has been determined to be a different construct from depression. ${ }^{35}$ 


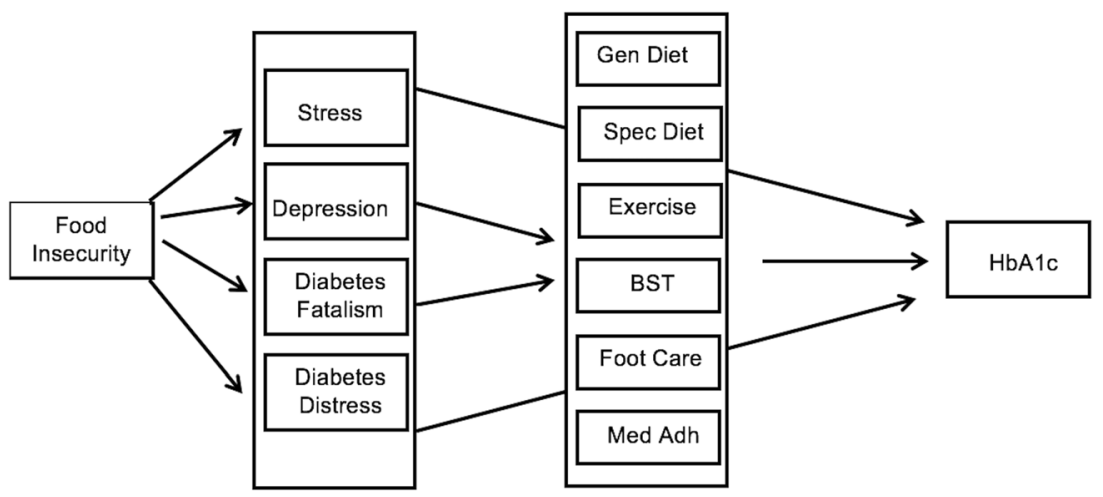

Figure 1 Initial Model indicating hypothesized pathways between food insecurity and glycemic control.

\section{Self-care Behaviors}

Self-care behaviors were measured using the 8-item Morisky Medication Adherence Scale (MMAS) and the 10-item Summary of Diabetes Self-Care Activities scale. ${ }^{36,37}$ The brief medication adherence scale asks about specific medicationtaking behavior with a Cronbach alpha of 0.83 indicating high internal consistency. ${ }^{36}$ The scale is scored such that higher scores indicate more adherence. The brief, validated, diabetes self-care questions can be scored to assess levels of adherence to general diet, specific diet, exercise, self-blood glucose testing, and foot care over the prior 7 days. ${ }^{37}$

\section{Demographics}

Demographics of the sample were measured using previously validated questions from the National Health Interview Survey, and included gender, age, race/ethnicity, marital status,

Table 1 Sample Demographics $(n=615)$

\begin{tabular}{ll}
\hline \hline & Mean \pm standard deviation or \% \\
\hline Age & $61.3 \pm 10.9$ \\
Diabetes duration & $12.3 \pm 9.1$ \\
Education (years of school) & $13.4 \pm 2.8$ \\
Employment (hours per week) & $12.5 \pm 19.0$ \\
Race & \\
White & 33.0 \\
Black & 64.9 \\
Other & 2.1 \\
Gender & 38.4 \\
Women & 61.6 \\
Men & 11.2 \\
Marital status & 49.7 \\
Never married & 39.1 \\
Married & 20.2 \\
Separated/divorced/widow & 21.4 \\
Income & 25.1 \\
<10,000 $\$ 19,999$ & 13.8 \\
\$20,000-\$34,999 & 19.5 \\
\$35,000-\$49,999 & 9.3 \\
\$50,000 or more & 20.2 \\
Insurance & 24.7 \\
None & 10.2 \\
Private & 23.9 \\
Medicare & 11.7 \\
Medicaid & \\
VA & \\
Other &
\end{tabular}

years of education, employment hours, household income, and insurance coverage ${ }^{38}$.

\section{Statistical Analysis}

All analyses were performed using Stata version 14, which allows path analyses using structured equation modeling (SEM). SEM is used to investigate direct and indirect effects and allows incorporation of multiple independent and dependent variables. ${ }^{39-41}$ First, we ran frequencies and means to summarize the sample demographics, psychosocial factors, self-care behaviors, and glycemic control for the sample. Secondly, SEM was used to investigate the relationship between food insecurity, psychosocial factors, self-care behaviors, and glycemic control based on a hypothesized model shown in Figure 1. Direct, indirect, and total effects were estimated using the maximum likelihood estimation procedure and standardized coefficients. The mlmv option in Stata was used which allows fullinformation maximum likelihood and retains variables rather than using listwise deletion. Prior to using this estimation procedure, assumptions for multivariate normality were tested and missing values were investigated. It was determined that no measures were heavily skewed, missing at random could be assumed, and no variable has more than $2 \%$ missing. A number of model fit statistics were investigated, following best practices of SEM, which included root square mean error of approximation (RSMEA) less than 0.05 , comparative fit index (CFI) greater than

Table 2 Descriptive Statistics for Measures Included in the Path Model

\begin{tabular}{ll}
\hline \hline & Mean values \pm standard deviation \\
\hline Glycemic control (HbA1c) & $7.9 \pm 1.8$ \\
Food insecurity & $1.32 \pm 1.93$ \\
Psychosocial factors & $6.1 \pm 6.0$ \\
$\quad$ Depression & $33.9 \pm 9.5$ \\
Diabetes fatalism & $5.3 \pm 3.3$ \\
Perceived stress & $1.6 \pm 0.7$ \\
Diabetes distress & \\
Self-care & $5.9 \pm 2.0$ \\
Medication adherence & $4.7 \pm 2.0$ \\
General diet & $4.0 \pm 1.6$ \\
Special diet & $2.6 \pm 2.2$ \\
Exercise & $4.6 \pm 2.5$ \\
Blood sugar testing & $4.3 \pm 2.5$ \\
Foot care &
\end{tabular}


Table 3 Pairwise Correlations of All Measures Included in Path Model

\begin{tabular}{|c|c|c|c|c|c|c|c|c|c|c|c|}
\hline & 1 & 2 & 3 & 4 & 5 & 6 & 7 & 8 & 9 & 10 & 11 \\
\hline 1. Food insecurity & - & - & - & - & - & - & - & - & - & - & - \\
\hline 2. Depression & $0.34 *$ & - & - & - & - & - & - & - & - & - & - \\
\hline 3. Fatalism & $0.09 *$ & $0.26^{*}$ & - & - & - & - & - & - & - & - & - \\
\hline 4. Stress & $0.43 *$ & $0.54 *$ & $0.24 *$ & - & - & - & - & - & - & - & - \\
\hline 5. Distress & $0.36^{*}$ & $0.66^{*}$ & $0.31 *$ & $0.45^{*}$ & - & - & - & - & - & - & - \\
\hline 6. General diet & $-0.20 *$ & $-0.26^{*}$ & -0.06 & $-0.22 *$ & $-0.33 *$ & - & - & - & - & - & - \\
\hline 7. Specific diet & $-0.14 *$ & $-0.18^{*}$ & -0.06 & $-0.22 *$ & $-0.23 *$ & $0.36^{*}$ & - & - & - & - & - \\
\hline 8. Exercise & $-0.10 *$ & $-0.21 *$ & $-0.09 *$ & $-0.13 *$ & $-0.17 *$ & $0.29 *$ & $0.15^{*}$ & - & - & - & - \\
\hline 9. $\mathrm{BSG}$ & $-0.12 *$ & -0.07 & -0.01 & $-0.11 *$ & $-0.10 *$ & $0.21 *$ & $0.19 *$ & $0.11 *$ & - & - & - \\
\hline 10. Foot care & -0.03 & -0.05 & $-0.09 *$ & -0.07 & -0.07 & $0.22 *$ & $0.22 *$ & $0.12 *$ & $0.28 *$ & - & - \\
\hline 11. Med adh & $-0.25 *$ & $-0.30^{*}$ & -0.07 & $-0.32 *$ & $-0.36^{*}$ & $0.28 *$ & $0.26^{*}$ & $0.13 *$ & $0.17 *$ & $0.23 *$ & - \\
\hline 12. HbA1c & $0.15^{*}$ & $0.16^{*}$ & $0.08 *$ & $0.12^{*}$ & $0.27 *$ & $-0.12 *$ & -0.07 & $-0.10 *$ & $0.10 *$ & 0.03 & $-0.20 *$ \\
\hline
\end{tabular}

${ }^{*} p<0.05$. HbAlc, hemoglobin Alc; BSG, blood sugar testing; Med adh, medication adherence

0.9, and Tucker fit index (TFI) greater than $0.9 .^{42}$ Strength of relationship was assessed by standardized coefficients that were statistically significant $(p<0.05)$. The sample size of 615 is sufficient for the best practice of 20:1 (subject to variable) ratio that allows us to maintain $80 \%$ power while providing stability of parameter estimates.

\section{RESULTS}

Table 1 provides sample demographics. The mean age was 61.3 years and the mean diabetes duration was 12.3 years. The majority of participants were non-Hispanic black (64.9\%), men (61.6\%), and insured. Table 2 provides descriptive statistics for all variables incorporated into the path model, and Table 3 provides correlations between all variables. The mean $\mathrm{HbAlc}$ was $7.9 \%$, and mean food insecurity score was 1.32 out of a possible high score of 6 .

Table 4 presents the standardized direct, indirect, and total effects for the relationship between food insecurity, psychosocial factors, self-care behaviors, and glycemic control, and Figure 2 shows the final model with only significant paths indicated. The standardized estimates shown in Table 3 and Figure 2 are interpreted as change in standard deviation of the outcome resulting from a change of 1 standard deviation in the predictor, and therefore can be compared with each other to understand the strength of the relationship. In the final model $\left(\operatorname{chi}^{23}=11.17, p<0.01\right.$, RMSEA $=0.067$, CFI $=0.99$, TLI $=$ $0.87)$, food insecurity was directly associated with perceived stress $(r=0.43, p<0.001)$, diabetes distress $(r=0.36, p<$ $0.001)$, depression $(r=0.34, p<0.001)$, and diabetes fatalism $(r=0.09, p=0.03)$. Diabetes distress was directly associated with glycemic control $(r=0.25, p<0.001)$, as was blood sugar testing $(r=0.14, p=0.001)$ and medication adherence $(r=-$ $0.14, p=0.002$ ). While depression was directly associated with exercise $(r=-0.15, p=0.007)$, perceived stress and diabetes distress were associated with general diet (distress $r=$ $-0.28, p<0.001$ ), specific diet (stress $r=-0.14, p=0.005$; distress $r=-0.17, p=0.001$ ), and medication adherence (stress $r=-0.17, p<0.001$; distress $r=-0.26, p<0.001$ ). Significant indirect effects include food insecurity and glycemic control $(r=0.08, p<0.001)$, general diet $(r=-0.13, p<$
$0.001)$, specific diet $(r=-0.12, p<0.001)$, exercise $(r=-$ $0.08, p<0.001)$, and medication adherence $(r=-0.17, p<$ $0.001)$. Investigating the significant direct relationships shown in Figure 2 that exist within the significant indirect pathways suggests food insecurity may be indirectly associated to exercise through depression, food insecurity may be indirectly associated with diet and medication adherence through stress and diabetes distress, and food insecurity may be indirectly associated with glycemic control through diabetes distress.

\section{DISCUSSION}

Using a sample of adults with diabetes, we found significant direct effects between food insecurity and all four psychosocial factors included in the model (depression, diabetes fatalism, perceived stress, and diabetes distress). The strength of this relationship varied, with the strongest relationship for food insecurity being with perceived stress. Food insecurity was also indirectly associated with (a) exercise through the pathway of depression, (b) diet and medication adherence through pathways of stress and diabetes distress, and (c) glycemic control through the pathway of diabetes distress. After accounting for the variance from food insecurity and psychosocial factors, the strongest self-care relationships with glycemic control were medication adherence and blood sugar testing. These results provide insight on psychosocial and behavioral targets for programs targeting individuals who have diabetes and are food insecure.

This study adds to the literature on food insecurity, stress, and diabetes outcomes by elucidating direct and indirect pathways through which food insecurity influences self-care and glycemic control. First, we found that food insecurity is associated with a number of psychosocial factors, suggesting interventions that focus on only one aspect of stress in the lives of food insecure adults with diabetes may not be sufficient. Many interventions, for instance, have focused on depression and diabetes, or diabetes specific distress factors, but the multifaceted stress experienced by food insecure individuals may be unique and therefore require a difference approach. As the field of stress research has grown, the lack of specificity regarding what type of stress influences health has 
Table 4 Standardized Direct, Indirect, and Total Effects for the Relationship between Food Insecurity, Psychosocial Factors, Selfcare Behaviors, and Glycemic Control

\begin{tabular}{|c|c|c|c|}
\hline & $\begin{array}{l}\text { Direct } \\
\text { effects }\end{array}$ & $\begin{array}{l}\text { Indirect } \\
\text { effects }\end{array}$ & $\begin{array}{l}\text { Total } \\
\text { effects }\end{array}$ \\
\hline \multicolumn{4}{|l|}{ Glycemic control } \\
\hline Food insecurity & 0.07 & $0.08 * * *$ & $0.15 * * *$ \\
\hline Diabetes fatalism & 0.02 & -0.01 & 0.01 \\
\hline Diabetes distress & $0.25 * * *$ & 0.03 & $0.28 * * *$ \\
\hline Depression & -0.06 & 0.02 & -0.05 \\
\hline Perceived stress & -0.04 & 0.01 & -0.02 \\
\hline General diet & -0.03 & - & -0.03 \\
\hline Specific diet & 0.003 & - & 0.003 \\
\hline Exercise & -0.06 & - & -0.06 \\
\hline Blood sugar testing & $0.14 * * *$ & - & $0.14 * *$ \\
\hline Foot care & 0.05 & - & 0.05 \\
\hline Medication & $-0.14 * *$ & - & $-0.14 * *$ \\
\hline \multicolumn{4}{|l|}{ adherence } \\
\hline \multicolumn{4}{|l|}{ General diet } \\
\hline Food insecurity & -0.08 & $-0.13 * * *$ & $-0.20 * * *$ \\
\hline Diabetes fatalism & 0.05 & - & 0.05 \\
\hline Diabetes distress & $-0.28 * * *$ & - & $-0.28 * * *$ \\
\hline Depression & -0.03 & - & -0.03 \\
\hline Perceived stress & -0.05 & - & -0.05 \\
\hline \multicolumn{4}{|l|}{ Specific diet } \\
\hline Food insecurity & -0.02 & $-0.12 * * *$ & $-0.14 * * *$ \\
\hline Diabetes fatalism & 0.02 & - & 0.02 \\
\hline Diabetes distress & $-0.17 * * *$ & - & $-0.17 * * *$ \\
\hline Depression & 0.01 & - & 0.01 \\
\hline Perceived stress & $-0.14^{* *}$ & - & $-0.14^{* *}$ \\
\hline \multicolumn{4}{|l|}{ Exercise } \\
\hline Food insecurity & -0.02 & $-0.08 * * *$ & $-0.10^{*}$ \\
\hline Diabetes fatalism & -0.03 & - & -0.03 \\
\hline Diabetes distress & -0.06 & - & -0.06 \\
\hline Depression & $-0.15^{* *}$ & - & $-0.15^{* *}$ \\
\hline Perceived stress & -0.01 & - & -0.01 \\
\hline \multicolumn{4}{|l|}{ Blood sugar testing } \\
\hline Food insecurity & -0.07 & -0.04 & $-0.11 * *$ \\
\hline Diabetes fatalism & 0.03 & - & 0.03 \\
\hline Diabetes distress & -0.08 & - & -0.08 \\
\hline Depression & 0.03 & - & 0.03 \\
\hline Perceived stress & -0.06 & - & -0.06 \\
\hline \multicolumn{4}{|l|}{ Foot care } \\
\hline Food insecurity & 0.02 & -0.04 & -0.02 \\
\hline Diabetes fatalism & -0.07 & - & -0.07 \\
\hline Diabetes distress & -0.06 & - & -0.06 \\
\hline Depression & 0.03 & - & 0.03 \\
\hline Perceived stress & -0.05 & - & -0.05 \\
\hline \multicolumn{4}{|l|}{ Medication adherence } \\
\hline Food insecurity & -0.08 & $-0.17 * * *$ & $-0.25 * * *$ \\
\hline Diabetes fatalism & 0.07 & - & 0.07 \\
\hline Diabetes distress & $-0.26^{* * *}$ & - & $-0.26^{* * *}$ \\
\hline Depression & -0.03 & - & -0.03 \\
\hline Perceived stress & $-0.17 * * *$ & - & $-0.17 * * *$ \\
\hline \multicolumn{4}{|l|}{ Diabetes fatalism } \\
\hline Food insecurity & $0.09 *$ & - & $0.09 *$ \\
\hline \multicolumn{4}{|l|}{ Diabetes distress } \\
\hline Food insecurity & $0.36^{* * * *}$ & - & $0.36 * * *$ \\
\hline \multicolumn{4}{|l|}{ Depression } \\
\hline Food insecurity & $0.34 * * *$ & - & $0.34 * * *$ \\
\hline \multicolumn{4}{|l|}{ Perceived stress } \\
\hline Food insecurity & $0.43 * * *$ & - & $0.43 * * *$ \\
\hline
\end{tabular}

$* p<0.05 ; * * p<0.01 ; * * * p<0.001$

Significant direct effects indicate direct association between variables. For example, higher levels of diabetes distress are associated with higher glycemic control. Significant indirect effects indicate pathways through which variables influence outcomes. For example, increased food insecurity is associated with glycemic control through psychosocial factors and self-care behaviors

limited the ability to develop highly effective interventions. ${ }^{43}$ Given food insecurity was associated with depression, perceived stress, diabetes distress, and fatalism, rather than focusing on addressing a type of stress, it may be more effective to focus on what both psychological and physiological stress responses have in common, which is cognitive appraisals. ${ }^{43}$ By considering the perception or appraisal of the stressor, rather than the stressor itself, interventions can address a variety of stressors that may exist in the lives of food insecure individuals, while also building personal resources to cope with stress and manage diabetes. Low SES individuals have been noted to have diverse and effective coping strategies, which can be drawn upon in the context of interventions focused on supporting improved self-management. ${ }^{44,45}$ Interventions need to be tailored to help food insecure individuals adapt and expand their coping and problem-solving capacity, while teaching reappraisal skills and stress management techniques.

A second important finding from this study was the variety of self-care factors that were directly and indirectly associated with food insecurity and glycemic control. Food insecurity was indirectly associated with exercise through the pathway of depression, indicating a need to address depressive symptoms in programs aimed at increasing physical activity in individuals experiencing food insecurity. Food insecurity was also indirectly associated with diet and medication adherence through pathways of perceived stress and diabetes distress. Extensive literature exists highlighting the importance of addressing diabetes distress to improve diabetes self-care behaviors $^{35,46}$; however, this relationship with food insecurity is a new finding. Finally, after taking into account the relationships of food insecurity, four psychosocial factors, and six self-care behaviors, blood sugar testing and medication adherence were directly associated with glycemic control. This highlights relationships that exist outside the psychosocial pathway accounted for in the model, and may be linked to a separate pathway. One possibility is that given blood sugar testing requires financial resources to purchase testing strips, and medication adherence requires financial resources to purchase medication, material resource needs experienced by individuals who are food insecure influence health in a direct way through access to diabetes supplies. Prior work has shown individuals who are food insecure are 4 times more likely to also report cost-related medication underuse ${ }^{47}$ Interventions for food insecure individual may need to target more than dietbased resource needs to fully address the resource limitations that influence diabetes outcomes.

Though this study used a sophisticated analysis that allows investigation of direct and indirect pathways, there are limitations of the results. First, the data cannot speak to causality as all measures were collected in a cross-sectional manner. Though the analyses were based on a hypothesized pathway, reverse causation for some elements of the model is possible. In particular, it is possible that glycemic control and psychosocial factors, such as depression, are related in a bi-directional manner. Secondly, path analysis tests only pathways hypothesized in the model; therefore, factors not incorporated into this analysis, such as healthcare access or quality of 


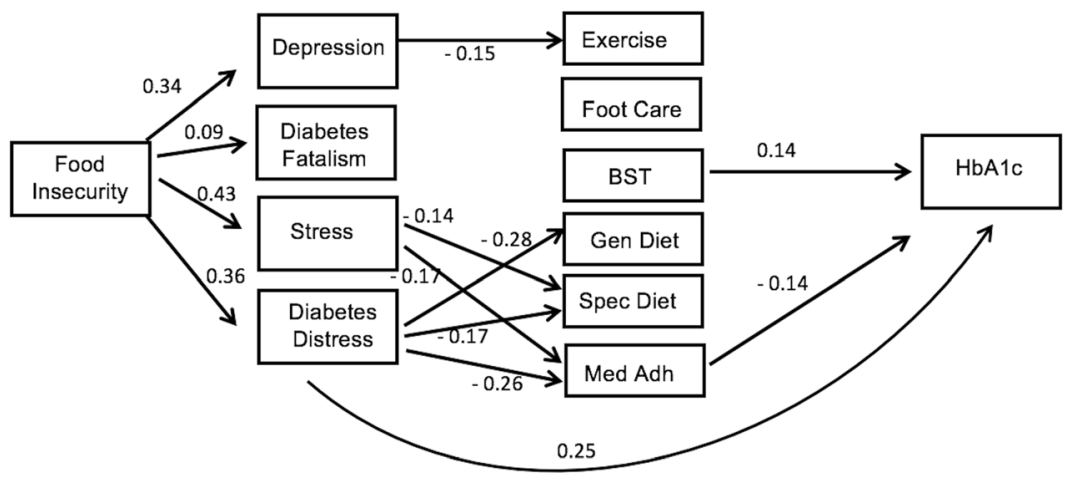

Note: Standardized estimates indicated. Overall model fit: chi2(3)=11.17, $p<0.01, \mathrm{RMSEA}=0.067, \mathrm{CFI}=0.99, \mathrm{TLI}=0.87$

Figure 2 Final model showing significant pathways between food insecurity and glycemic control.

diabetes care, may have additional influence. Thirdly, data for this analysis was collected in the southeastern United States, and therefore may not be generalizable to the entire US population.

\section{CONCLUSION}

In conclusion, food insecurity influences self-care behaviors indirectly via multiple psychosocial factors, and influences glycemic control indirectly through diabetes distress, supporting the hypothesis that stress is an important mechanism in food insecure populations. In addition, given the relationship between medication adherence and blood sugar testing remained after psychosocial and behavioral factors were taken into account, resources are needed beyond supplementation of healthy food to improve glycemic control in food insecure populations. Finally, programs to manage psychosocial concerns may need to be combined with resource or foodbased programs for food insecure populations with diabetes.

Corresponding Author: Rebekah J. Walker, PhD; Division of General Internal Medicine, Department of Medicine Medical College of Wisconsin, Milwaukee, WI 53226-3596, USA (e-mail: rebwalker@mcw.edu).

Author Contributions RJW, JAC, and LEE designed the study. RJW and LEE collected data, and conducted analyses. RJW drafted the manuscript. All authors reviewed and edited the manuscript, and contributed to interpretation of results and discussion of implications.

Funding Information Effort for this study was partially supported by the National Institute of Diabetes and Digestive Kidney Disease (K24DK093699, R01DK118038, R01DK120861, PI: Egede), the National Institute for Minority Health and Health Disparities (R01MD013826, PI: Egede/Walker) and the American Diabetes Association (1-19-JDF-075, PI: Walker).

\section{Compliance with Ethical Standards:}

Conflict of Interest: The authors declare that they do not have a conflict of interest.

\section{REFERENCES}

1. Coleman-Jensen A, Rabbitt MP, Gregory CA, Singh A. 2018. Household Food Security in the United States in 2017, ERR-256, U.S. Department of Agriculture, Economic Research Service

2. Gucciardi E, Vahabi M, Norris N, Del Monte JP, Farnum C. The Intersection between Food Insecurity and Diabetes: A Review. Curr Nutr Rep. 2014;3(4):324-332.

3. Berkowitz SA, Meigs JB, DeWalt D, Seligman HK, Barnard LS, Bright OJ, Schow M, Atlas SJ, Wexler DJ. Material need insecurities, control of diabetes mellitus, and use of health care resources: results of the Measuring Economic Insecurity in Diabetes study. JAMA Intern Med. 2015;175(2):257-65

4. Seligman HK, Bindman AB, Vittinghoff E, Kanaya AM, Kushel MB. Food insecurity is associated with diabetes mellitus: results from the National Health Examination and Nutrition Examination Survey (NHANES) 19992002. J Gen Intern Med. 2007;22(7):1018-23.

5. Berkowitz SA, Berkowitz TSZ, Meigs JB, Wexler DJ. Trends in food insecurity for adults with cardiometabolic disease in the United States: 2005-2012. PLoS One. 2017;12(6):e0179172.

6. Walker RJ, Grusnick J, Garacci E, Mendez C, Egede LE. Trends in food insecurity in the United States for individuals with pre-diabetes, undiagnosed diabetes, and diagnosed diabetes. JGIM. 2018. https:// doi.org/10.1007/s11606-018-4651-Z

7. Balistreri KS. A Decade of Change: Measuring the Extent, Depth and Severity of Food Insecurity. J Fam Econ Issues. 2016;37(3):373-82.

8. Strings S, Ranchod YK, Laraia B, Nuru-Jeter A. Race and Sex Differences in the Association between Food Insecurity and Type 2 Diabetes. Ethn Dis. 2016;26(3):427-34.

9. Vozoris NT, Tarasuk VS. Household food insufficiency is associated with poorer health. J Nutr. 2003;133(1):120-6.

10. Barnard LS, Wexler DJ, DeWalt D, Berkowitz SA. Material need support interventions for diabetes prevention and control: a systematic review. Curr Diab Rep. 2015;15(2):574.

11. Ippolito MM, Lyles CR, Prendergast K, Marshall MB, Waxman E, Seligman HK. Food insecurity and diabetes self-management among food pantry clients. Public Health Nutr. 2017;20(1):183-189.

12. Seligman HK, Davis TC, Schillinger D, and Wolf MS. Food insecurity is associated with hypoglycemia and poor diabetes self-management in a low-income sample with diabetes. J Health Care Poor Underserved. 2010; 21(4): 1227-1233.

13. Seligman HK, Schillinger D. Hunger and socioeconomic disparities in chronic disease. New Eng J Med. 2010; 363(1):6-9.

14. Seligman HK, Jacobs EA, Lopez A, Tschann J, Fernandez A. Food insecurity and glycemic control among low-income patients with type 2 diabetes. Diabetes Care. 2012;35(2):233-238.

15. Berkowitz SA, Baggett TP, Wexler DJ, Huskey KW, Wee CC. Food insecurity and metabolic control among U.S. adults with diabetes. Diabetes Care. 2013;36(10):3093-9.

16. Essien UR, Shahid NN, Berkowitz SA. Food Insecurity and Diabetes in Developed Societies. Curr Diab Rep. 2016;16(9):79. 
17. Lyles CR, Wolf MS, Schillinger D, et al. Food insecurity in relation to changes in hemoglobin Alc, self-efficacy, and fruit/vegetable intake during a diabetes educational intervention. Diabetes Care. 2013;36(6):1448-53.

18. Smalls BL, Gregory CM, Zoller JS, Egede LE. Assessing the relationship between neighborhood factors and diabetes related health outcomes and self-care behaviors. BMC Health Serv Res. 2015;15:445.

19. Heerman WJ, Wallston KA, Osborn CY, Bian A, Schlundt DG, Barto SD, Rothman RL. Food insecurity is associated with diabetes self-care behaviours and glycaemic control. Diabet Med. 2016;33(6):844-50.

20. Silverman J, Krieger J, Kiefer M, Hebert P, Robinson J, Nelson K. The Relationship Between Food Insecurity and Depression, Diabetes Distress and Medication Adherence Among Low-Income Patients with PoorlyControlled Diabetes. J Gen Intern Med. 2015;30(10):1476-80.

21. Hamelin AM, Habicht JP, Beaudry M. Food insecurity: consequences for the household and broader social implications. J Nutr. 1999; 129: 525S$8 \mathrm{~S}$.

22. Gallo LC, Matthews KA. Understanding the association between socioeconomic status and physical health: do negative emotions play a role? Psychol Bull. 2003;129:10-51.

23. Kollannoor-Samuel G, Vega-López S, Chhabra J, Segura-Pérez S, Damio G, Pérez-Escamilla R. Food insecurity and low self-efficacy are associated with health care access barriers among Puerto-Ricans with type 2 diabetes. J Immigr Minor Health. 2012;14(4):552-62.

24. Montgomery J, Lu J, Ratliff S, Mezuk B. Food Insecurity and Depression Among Adults with Diabetes: Results from the National Health and Nutrition Examination Survey (NHANES). Diabetes Educ. 2017;43(3):260-271.

25. Mayer VL, McDonough K, Seligman H, Mitra N, Long JA. Food insecurity, coping strategies and glucose control in low-income patients with diabetes. Public Health Nutr. 2016;19(6):1103-11.

26. Walker RJ, Williams JS, Egede LE. Pathways between food insecurity and glycemic control in individuals with type 2 diabetes. Public Health and Nutrition. 2018 8: 1-8.

27. Mendola ND, Chen T-C, Gu Q, Eberhardt MS, Saydah S. Prevalence of total, diagnosed, and undiagnosed diabetes among adults: United States, 2013-2016. NCHS Data Brief, no 319. Hyattsville, MD: National Center for Health Statistics. 2018.

28. Bickel G, Nord M, Price C, Hamilton W, Cook J. Guide to Measuring Household Food Security, Revised 2000. US Department of Agriculture, Food and Nutrition Scervice, Alexandria VA. 2000.

29. Blumberg SJ, Bialostosky K, Hamilton WL, Briefel RR. The effectiveness of a short form of the household food security scale. Am J Public Health. 1999; 89: 1231-1234.

30. Kroenke K, Spitzer RL, Williams JB. (2001) The PHQ-9: validity of a brief depression severity measure. J Gen Intern Med. 16:606-613.

31. Egede LE, Ellis C. Development and psychometric properties of the 12item diabetes fatalism scale. $J$ Gen Intern Med. 2010;25:61-66.

32. Cohen, S. and Williamson, G. Perceived Stress in a Probability Sample of the United States. Spacapan, S. and Oskamp, S. (Eds.) The Social Psychology of Health. Newbury Park: Sage, 1988.
33. Andreou E, Alexopoulos EC, Lionis C, Varvogli L, Gnardellis C, Chrousos GP, Darviri C. Perceived stress scale: reliability and validity study in Greece. Int J Environ Res Public Health. 2011; 8:3287-3298.

34. Fisher L, Glasgow RE, Mullan JT, Skaff, MM, Polonsky WH. Development of a brief diabetes distress screening instrument. Annuls Fam Med. 2008.;6(3):246-252.

35. Fisher L, Gonzalez JS, Polonsky WH. The confusing tale of depression and distress in patients with diabetes: a call for greater clarity and precision. Diabet Med 2014; 31(7): 764-772.

36. Morisky, DE, Green LW, Levine DM. Concurrent and predictive validity of a self-reported measure of medication adherence. Medical Care. 1986, 24:67-74.

37. Toobert DJ, Hampson SE, Glasgow RE. The summary of diabetes selfcare activities measure: results from 7 studies and a revised scale. Diabetes Care. 2000; 23(7):943-950.

38. National Center for Health Statistics. Survey Questionnaire, National Health Interview Survey, 2002. National Center for Health Statistics, Hyattsville. 2004.

39. Kline RB. Principles and Practice of Structural Equation Modeling, 4th Edition. New York: Guilford Press, 2016.

40. Schumacker RE, Lomax RG. A Beginner's Guide to Structural Equation Modeling, 3rd ed. New York: Taylor and Francis Group, 2010.

41. Schreiber JB. Core reporting practices in structural equation modeling. Res Soc Admin Pharm 2008;4:83-97.

42. Hooper D, Caughlan J, Mullen MR. Structural equation modeling: guidelines for determining model fit. Electron $J$ Business Res Methods 2008; 6:53-60.

43. Epel ES, Crosswell AD, Mayer SE, Prather AA, Slavich GM, Puterman E, Mendes WB. More than a feeling: a unified view of stress measurement for population science. Frontiers Neuroendocrinology. 2018; 49: 146-169.

44. Dammann KW, Smith C. Factors affecting low-income women's food choices and the perceived impact of dietary intake and socioeconomic status on their health and weight. J Nutr Educ Behav 2009;41:242-253.

45. Anater AS, McWilliams R, Watkin CA. Food acquisition practices used by food-insecure individuals when they are concerned about having sufficient food for themselves and their households. J Hunger Environ Nutr 2011;6:27-44.

46. Hessler DM, Fisher L, Polonsky WH, Masharani U, Strycker LA, Peters $\mathrm{AL}$, Blumer I, Bowyer V. Diabetes distress is linked with worsening diabetes management over time in adults with type 1 diabetes. Diabet Med. 2017; 34(9); 1228-1234.

47. Berkowitz SA, Seligman HK, Choudhry NK. Treat or eat: food insecurity, cost-related medication underuse, and unmet needs. Am J Med. 2014; 127(4): 303-310

Publisher's Note Springer Nature remains neutral with regard to jurisdictional claims in published maps and institutional affiliations. 